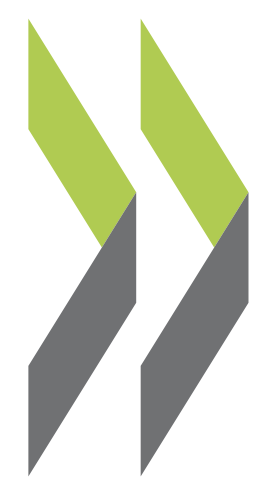

CELE Exchange, Centre for Effective Learning Environments 2010/04

\title{
Developing International Campuses of Excellence in Spain
}

\section{Màrius Rubiralta,}

Luis Delgado 


\section{Developing international campuses of excellence in Spain}

By Màrius Rubiralta and Luis Delgado, Ministry of Education, Spain

In 2009 the Secretary General of Universities (SGU) of the Spanish Ministry of Education launched a new programme to foster the modernisation and internationalisation of Spanish university campuses. This initiative focused on teaching, research and aspects of technology transfer, but also developing the campus into an integral social model which interacts with its territorial environment. Results so far have been positive, and are contributing to the creation of sustainable, environmentally integrated university campuses.

\section{THE CHALLENGES OF THE SPANISH UNIVERSITY SYSTEM: STRATEGY UNIVERSITY 2015}

The challenges faced by the Spanish university system are on the whole common to other EU countries, although some are specific to Spain due to the largely decentralised administrative structure of the country, as university education competences have been transferred to the regions (Autonomous Communities). The Bologna process called for a common framework for university education within the European Higher Education Area (EHEA). Although many Spanish universities have almost accomplished this curricular reform, other reforms under the Modernisation Agenda for Universities, involving, for example, governance reform, business links, internationalisation, social dimensions, quality and funding reforms, have still to be completed.

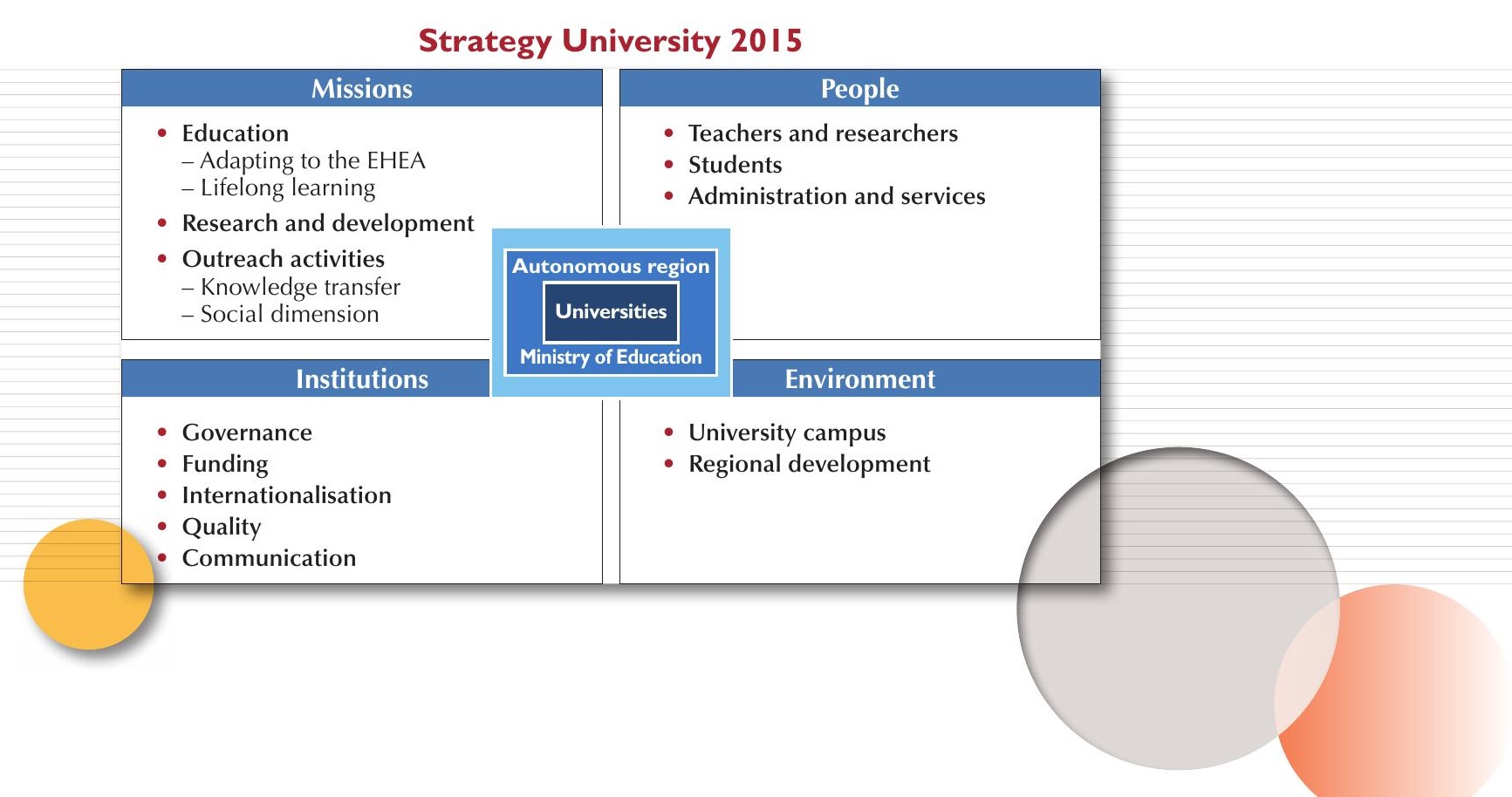


In order to foster the modernisation of universities and allow them to fulfil their potential to contribute to the development of a knowledge-based economy and society, in 2008 the Spanish government launched Strategy University 2015 (SU-2015). This initiative promotes the development of highly internationalised, well managed and well funded universities. The objective is that they contribute to the global production of knowledge, innovation and the sustainable economic development of their territorial environments.

The strategy has a time horizon of 2015. It focuses on four key dimensions and fifteen subcategories: missions: education, research, knowledge transfer, social responsibility; people: academics and researchers, students and administrative personnel; institutions: governance, funding, internationalisation, quality and evaluation and communication; and environment: campus, university-city-territory and regional development.

\section{THE INTERNATIONAL CAMPUS OF EXCELLENCE}

Spain has a total of 77 universities, of which 50 are public; they are spread out over 232 campuses of which 21 offer distance learning. In 2008-09 there were 1504276 university students in all. Depending on the geographical location of the campus (urban, metropolitan, regional) and the distribution of campuses per autonomous community (region with only one university with several campuses in the region, or region with several universities), there are different types of university campus. These range from the local mono-campus to the regional or global multi-campus. Catalonia, Madrid and Andalusia account for almost $75 \%$ of the total number of university campuses.

\section{The number of universities, campuses and students in Spain}

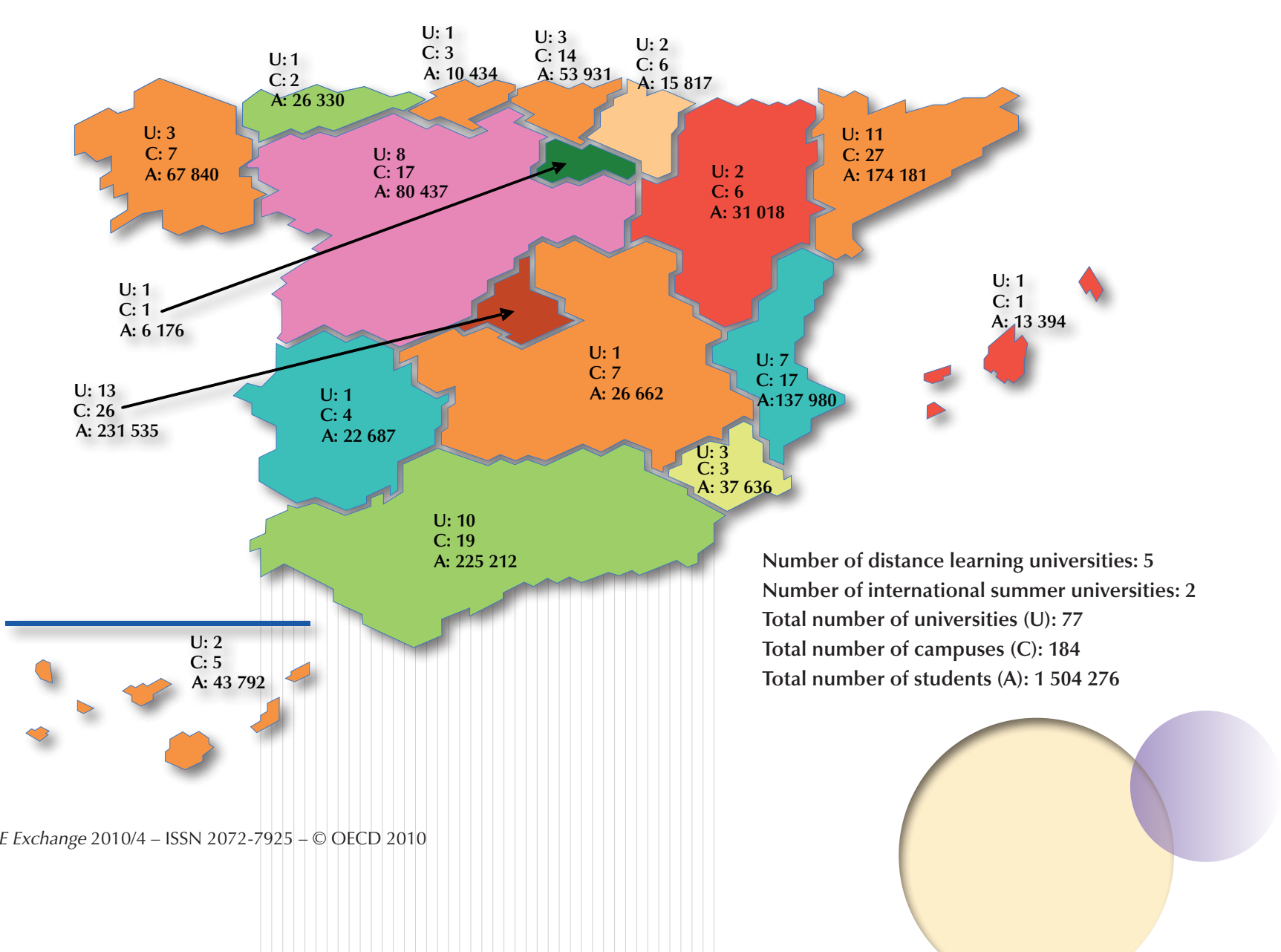


Within the framework of SU-2015, a new programme called International Campus of Excellence (CEI) was launched in July 2009. CEl's overarching goal is to make Spanish university campuses among the best in Europe, to promote their international renown and enhance the strengths of the Spanish university system. It aims to improve the quality of teaching and research in Spanish universities, as well as to achieve advances in innovation. It fosters public and private strategic aggregations among universities, other research institutions and businesses located within the campus. It promotes diversification and specialisation with a focus on excellence, and develops knowledge ecosystems which contribute to regional economic development, social cohesion and employment. The programme is managed by the Ministry of Education in collaboration with the Ministry of Science and Innovation and the support of the Autonomous Communities.
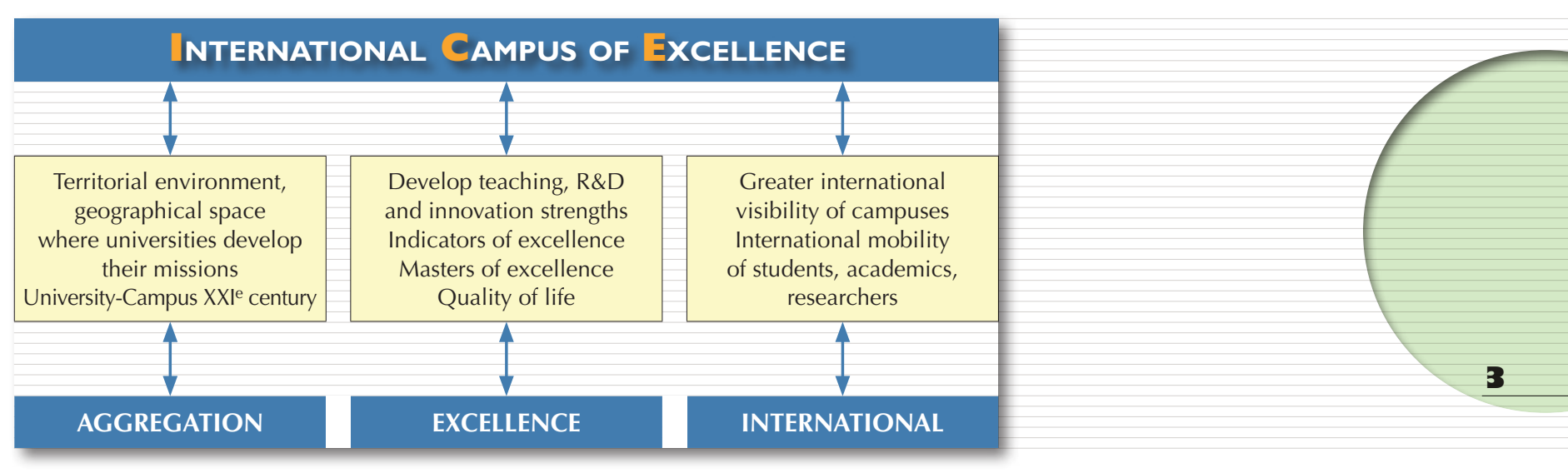

Thanks to CEl, a new concept of the university campus has evolved, involving interaction between universities and research and technological centres, scientific and technological parks, businesses and other agents. This interaction should facilitate the development of territorial education, research and innovation communities which strive for international excellence in a specific domain.

This new concept aims to promote campuses which are socially and economically integrated within their surrounding urban or regional area. The campus will need to make efforts to achieve high quality services and environmental sustainability, i.e. be dynamic and sustainable so that that it can help increase the attractiveness of the area for international students, academics and researchers as well as for knowledge-related investors. It involves adapting teaching and learning spaces according to the goals of the European Higher Education Area.

Project for a geological garden, University of Barcelona

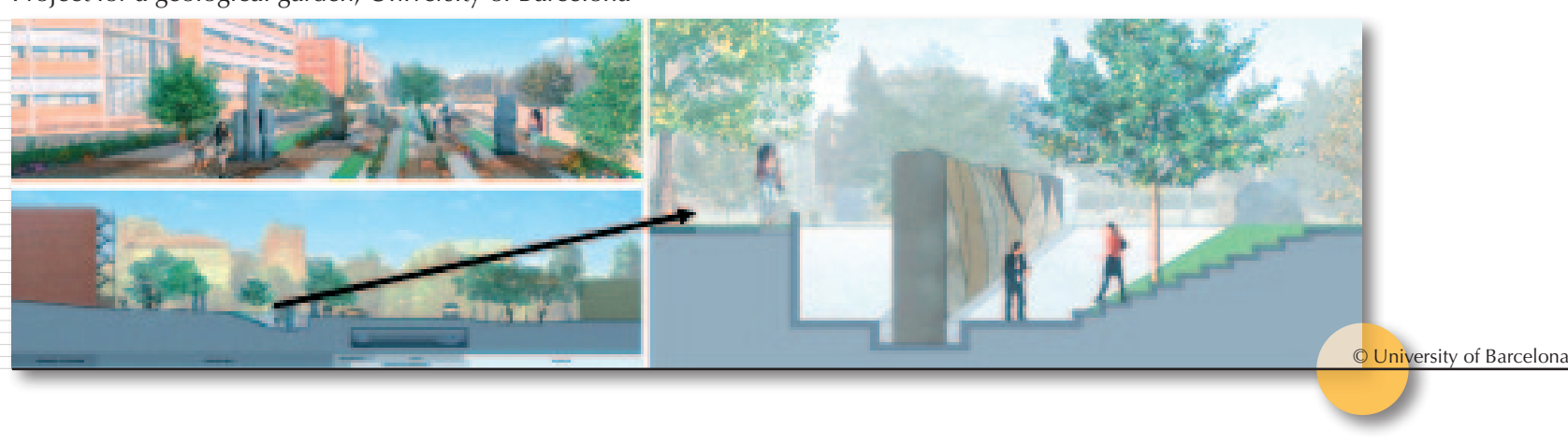




\section{THE SELECTION PROCESS AND INITIAL RESULTS}

The programme started off with a budget of EUR 203 million (in addition to EUR 150 million advanced in 2008). Through a competitive process, it awards grants of up to EUR 53 million and as well as loans (EUR 150 million in 2009). These sums are intended for the Autonomous Communities where the selected campuses are located to help them implement their strategic plans to move towards international excellence.

The first call for proposals, which closed on 8 September 2009, resulted in 51 responses and involved $84 \%$ of Spanish public universities and 8 private institutions; this high level of results illustrates the success of the programme.

The evaluation criteria for competing campuses are as follows:

1. Improved teaching and adaptation of teaching spaces according to the European Higher Education Area, as well as the renovation of teaching buildings.

2. Improvements in science and knowledge transfer of university-based results to businesses.

3. Sustainability: transformation of the campus; the development of an integral social model; interaction with the territorial environment.
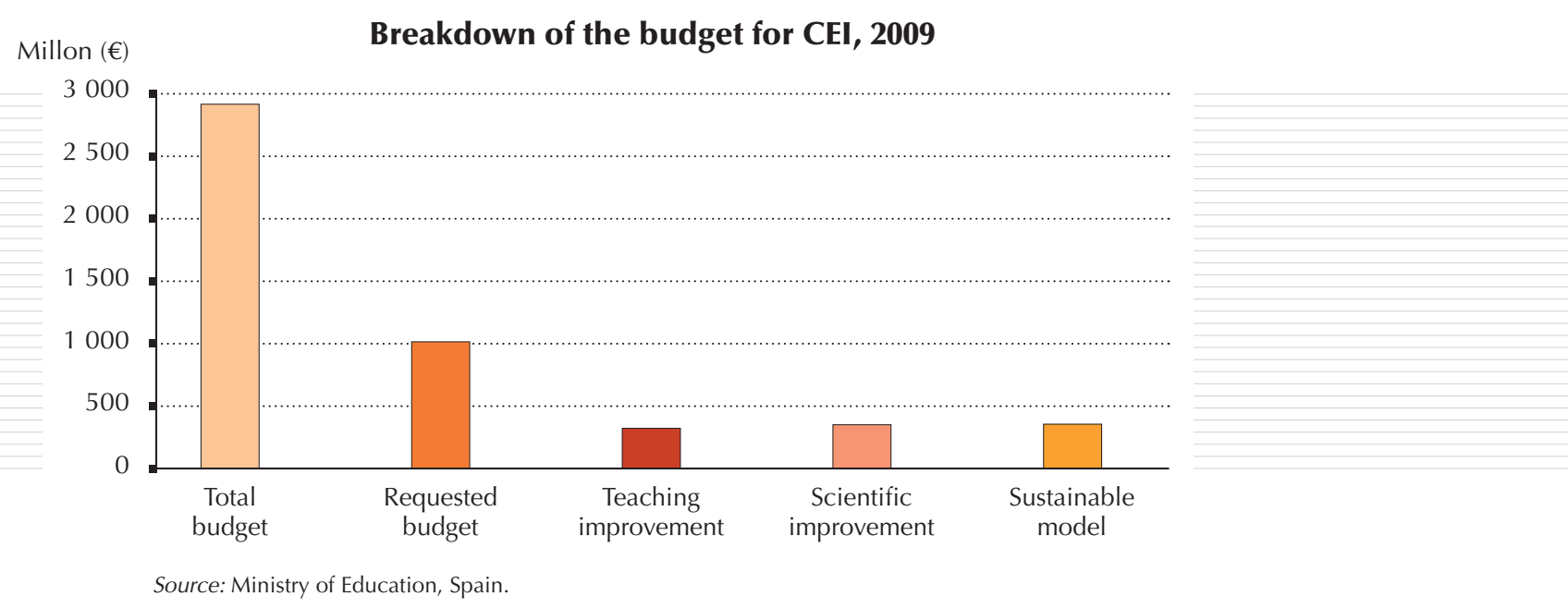

An initial evaluation was made by a technical committee in order to pre-select 18 proposals. The ambition, feasibility and adequacy of the actions and goals proposed by each institution were assessed against each of the evaluation criteria. Architects and representatives from the ministries of environment, labour, equality and housing participated in the technical committee. They assessed elements related to the social model: student life, equity and gender aspects, student housing, restoration of buildings, urbanism, etc.

Each of the 18 institutions received up to EUR 200000 to elaborate a detailed action plan to transform their existing campus into an International Campus of Excellence. The selected projects were defended by the project co-ordinators and rectors in a public session chaired by the ministers of education, science and innovation in front of an international commission composed of 9 independent and experienced personalities. Over 600 people from the political world attended, representing the Spanish state, regions, parliament, senate, municipalities, etc. The university world was represented by rectors, social councils, students, academics and researchers. Finally, there were representatives from business and civil society as well as the social and economic world. 
The international commission selected a total of five campuses for the award of International Campus of Excellence (CEI): Barcelona Knowledge Campus (University of Barcelona and Polytechnic University of Catalonia), University Campus of La Moncloa (University Complutense of Madrid and Polytechnic University of Madrid), Campus Carlos III (University Carlos III of Madrid), UAB-CEI Knowledge and Innovation (Autonomous University of Barcelona) and UAM-CSIC CEI (Autonomous University of Madrid - CSIC). Four projects qualified as CEI of regional interest and nine projects qualified as promising projects to be proposed for the CEl award in subsequent calls.

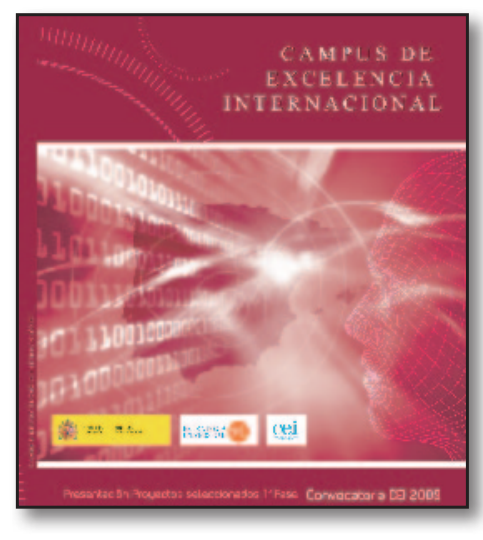

In conclusion, it is expected that the programme will contribute to improve the teaching and research quality of Spanish universities, as well as advances in innovation. Furthermore, the fact that urban, architectural, environmental and social aspects will be taken into account will facilitate the emergence of integral urban projects, including didactic, healthy, sustainable and accessible campuses. These will match local needs in relation to transportation, services, productive areas, research, innovation, culture and social life. The region as a whole will benefit from the repercussions of the International Campus of Excellence award.

For more information, contact:

Luis Delgado

Deputy Director, General Modernisation and Promotion of University-based Research Ministry of Education

Paseo del Prado, 28

28014 Madrid

Spain

Tel.: +34 915065647

E-mail: luism.delgado@educacion.es

International Campus of Excellence (CEI) public presentation of projects, 25 November 2009
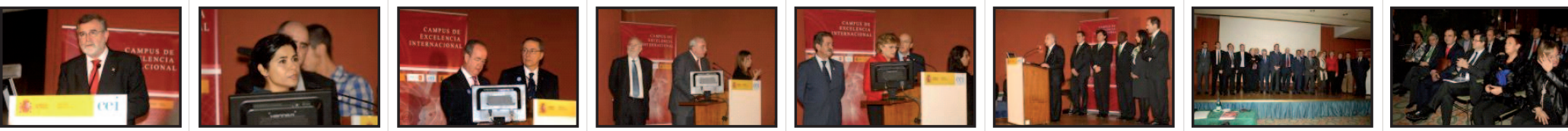


\section{ORGANISATION FOR ECONOMIC CO-OPERATION AND DEVELOPMENT}

The OECD is a unique forum where the governments of 30 democracies work together to address the economic, social and environmental challenges of globalisation. The OECD is also at the forefront of efforts to understand and to help governments respond to new developments and concerns, such as corporate governance, the information economy and the challenges of an ageing population. The Organisation provides a setting where governments can compare policy experiences, seek answers to common problems, identify good practice and work to co-ordinate domestic and international policies.

The OECD member countries are: Australia, Austria, Belgium, Canada, the Czech Republic, Denmark, Finland, France, Germany, Greece, Hungary, Iceland, Ireland, Italy, Japan, Korea, Luxembourg, Mexico, the Netherlands, New Zealand, Norway, Poland, Portugal, the Slovak Republic, Spain, Sweden, Switzerland, Turkey, the United Kingdom and the United States. The Commission of the European Communities takes part in the work of the OECD.

OECD Publishing disseminates widely the results of the Organisation's statistics gathering and research on economic, social and environmental issues, as well as the conventions, guidelines and standards agreed by its members.

This work is published under the responsibility of the Secretary General of the OECD. The opinions expressed and arguments employed herein do not necessarily reflect the official views of the Organisation or of the governments of its member countries.

You can copy, download or print OECD content for your own use, and you can include excerpts from OECD publications, databases and multimedia products in your own documents, presentations, blogs, websites and teaching materials, provided that suitable acknowledgment of OECD as source and copyright owner is given. All requests for public or commercial use and translation rights should be submitted to rights@oecd.org. Requests for permission to photocopy portions of this material requests for public or commercial use and translation rights should be submitted to rights@oecd.org. Requests for permission to photocopy portions of this material
for public or commercial use shall be addressed directly to the Copyright Clearance Center (CCC) at info@copyright.com or the Centre français d'exploitation du droit de copie (CFC) contact@cfcopies.com. 